\title{
Professional titles matter
}

\author{
Academic titles are often used without much thought; however, a recent discussion on social media has highlighted \\ how the use of a title can have important implications for individuals, in particular women, and how they can be \\ perceived as elitist by the general public.
}

\begin{abstract}
$\mathrm{n}$ June, a tweet from cultural historian Dr Fern Riddell (@FernRiddell) triggered over 1,500 comments, 15,000 likes and an ongoing debate that has hit the headlines and coined the hashtag \#ImmodestWomen. The tweet called attention to an example of gender bias that many academics experience in their day to day lives; that their professional title of 'Dr', which Riddell notes identifies her as an expert, is dropped in favour of Ms/Mrs/Miss as a form of address. Support for Riddell emerged from both women and men, with women in particular sharing similar stories and pointing out
\end{abstract} that their professional titles represent the advanced qualifications that have been earned through hard work. Notably, during the ensuing discussions, many women changed their Twitter display names to include their academic title. Unsurprisingly, the social media response was not uniformly supportive, with some noting that insisting that other people use 'Dr' when addressing oneself is entitled, arrogant or insecure, while others felt that titles should not define a person. Such reactions have an element of 'doctoral shaming', where individuals are dismissive of, or take offense to, academic qualifications, and label those with such expertise as elitist. While most individuals will use their titles without discrimination, such experiences are by no means rare, and unfortunately factors such as gender, race, religion and sexual orientation can play a part in being on the receiving end.

A quick poll of the Nature Microbiology editorial team (with three male and three female editors) supports the idea that gender bias, with regards to the use of professional titles, is not limited to active researchers. While none of the male editors could find examples of receiving e-mails addressed to 'Mr' since the journal launched in 2015, two out of three female editors have received e-mails on several occasions addressed to 'Mrs' or 'Ms' rather than 'Dr'. While such examples are rare and more likely to be an innocent mistake than an intentional slight, it does suggest that there may on-occasion be unconscious bias experienced by our female editors that is not faced by male colleagues. While such experiences could be dismissed as a minor, they do discredit the expertise of the recipient and provide another example of bias, whether conscious or not, in academic life.

Following Riddell's tweet, many female academics and clinicians have shared their experiences of gender bias, emphasizing how important their professional titles prove in the workplace. Female medical doctors have reported being referred to as nurses by their patients or junior male colleagues, and female professors have been addressed as 'Miss' by their students, who at the same time call younger male colleagues 'Professor'. This has important implications for respect and authority in the workplace, and undermines the hard work and expertise of the woman in question. A study looking at the use of professional titles in speaker introductions during Internal Medicine Grand Rounds (J. A. Files et al. J. Womens Health 26, 413-419; 2017) found that women were more likely to use professional titles to introduce male and female speakers, whereas men were significantly less likely to use a female speaker's professional title ( $95 \%$ compared to $49.2 \%$, respectively). Furthermore, this phenomenon is not isolated to professional titles, but also the use of surnames when referring to a person; male scientists are more likely than their female counterparts to be referred to by surname, which has implications for perceived success, notoriety and eminence in the field (S. Atir and M. J. Ferguson, Proc. Natl Acad. Sci. USA 125, 7278-7283; 2018). The use of an academic title not only has implications for prominence and expertise, but others also prefer the title 'Dr' because it is gender neutral and not related to marital status, removing potential preconceived prejudices for those who choose not to be labelled by traditional gender definitions.

One question that was raised in response to these discussions was whether academics should be using professional titles in their non-professional lives. Some argue that 'Dr' or 'Professor' should be reserved for correspondence with colleagues and other academics, with students and patients, and on published work, but avoided on credit cards, passports and in other situations that require a title. Can using an academic title in such situations be considered elitist or showing off about one's achievements? Certainly having a $\mathrm{PhD}$ has no impact on an individual's ability to board a flight or book into a hotel, and shouldn't deserve preferential treatment over someone who doesn't have a doctorate. Yet most people with PhDs will use 'Dr' broadly when interacting with any organization in a formal manner, rather than limiting them to activities only relating to work. Conversely, since formal address can be somewhat stifling in social interactions, titles are often pushed aside once familiarity has developed with colleagues, students and patients. For example, in our correspondence with authors, reviewers and other researchers, we editors generally move to first name terms having e-mailed a few times or met in person, irrespective of their formal title or gender.

While this debate has sparked a range of responses from academics, clinicians and the general public, raising the public profile of female doctors is surely a positive thing. It may encourage others to make a conscious choice to refer to women with the appropriate qualifications as 'Dr', and also inspire other young women to continue studying to attain advanced qualifications and the opportunities that they bring. Furthermore, this debate does not only have implications for women. Those who have earned a professional title have worked hard for many years to gain their qualifications and pursue a career in science, sometimes at the detriment of other parts of their life. These achievements should not be hidden away or belittled by those who intentionally avoid using an individual's appropriate title. However, it is also important to bear in mind the need to counter what seems to be a growing divide between different sections in society and we must tackle concerns regarding elitism with care, so that expertise in others (whether they are defined by a professional title or not), can be recognized as valuable both individually and collectively. As such, a measured approach in responding to being incorrectly addressed is advisable, whether this was intended or accidental. These opportunities can be used to open up a dialogue with those who may not realize the unintended consequences of that dropped title.

Published online: 26 November 2018 https://doi.org/10.1038/s41564-018-0320-6 